\title{
Climate change analogue analysis of ski tourism in the northeastern USA
}

\author{
J. Dawson*, D. Scott, G. McBoyle \\ Department of Geography and Environmental Management, University of Waterloo, 200 University Ave. West, \\ Waterloo, Ontario N2L 3G1, Canada
}

\begin{abstract}
Detrimental impacts of climate change on the international ski tourism industry have been projected in numerous studies. Modeling-based studies project shortened ski seasons and increased snowmaking requirements under warmer temperatures. The present study uses a climate change analogue approach to examine how a wider range of ski area performance indicators were affected by anomalously warm winters in the Northeast region of the USA. The record warm winter of 2001-2002 is representative of projected future average winter climate conditions in the USA Northeast under a high greenhouse gas emission scenario for the 2040-2069 period and was used as one climate change analogue for this analysis. The 1998-1999 ski season was also used as a climate change analogue as it represents the last of 3 consecutive warm winters (1997 to 1999) that are representative of a mid-range emissions scenario projected for the 2040-2069 period. Ski area performance indicators for the 2001-2002 and 1998-1999 analogue years were compared to the climatically normal (based on 1961-1990 means) years of 2000-2001 and 2004-2005. The indicators examined include: ski season length, snowmaking (hours of operation and \% energy utilized as a proxy for fuel costs), total skier visits and operating profit (\% of total gross fixed assets). The effect of ski season length during the climate change analogue years is compared with modeled effects for the region. The differential vulnerability of small, medium, large and extra-large ski areas was also examined and the greatest economic effects were found among small and extra large ski areas.
\end{abstract}

KEY WORDS: Ski tourism $\cdot$ Analogue $\cdot$ Climate change $\cdot$ Northeastern USA

\section{INTRODUCTION}

Weather and climate significantly influence the tourism and recreation industry (Perry 1997), particularly in sectors which rely heavily on natural resources for participation. The multi-billion dollar international ski industry has been identified in multiple studies and government assessments as highly vulnerable to changes in regional and local climate because of the strong reliance on natural snow availability or cold temperatures to make snow (Australia: Galloway 1988, Hennessy et al. 2003, Bicknell \& McManus 2006; Austria: Breiling \& Charamza 1999, Abegg et al. 2007, Wolfsegger et al. 2008; Canada: McBoyle \& Wall 1987 , 1992, Lamothe \& Périard Consultants 1988, Scott et al. 2003, 2006, 2007, Scott \& McBoyle 2007; France, Ger- many and Italy: Abegg et al. 2007; Japan: Fukushima et al. 2002; Sweden: Moen \& Fredman 2007; Switzerland: Koenig \& Abegg 1997, Elsasser \& Messerli 2001, Elsasser \& Bürki 2002; USA: Lipski \& McBoyle 1991, Hayhoe et al. 2004, Casola et al. 2005, Dawson \& Scott 2007, Scott et al. 2008).

Most of the above studies examining climate change impacts on the international ski industry utilize a variety of modelling-based methodologies to estimate future changes in snow conditions and supply-side indicators (e.g. ski season length and snow reliable ski areas). The majority of these studies neglect to consider the wide range of adaptation strategies that can be implemented in ski areas in order to compensate for changes in natural snow conditions (see Elsasser \& Bürki 2002, Scott \& McBoyle 2007). Exceptions are sev- 
eral studies conducted in North America (Scott et al. 2003, 2006, Dawson \& Scott 2007, Scott et al. 2008) and Australia (Hennessy et al. 2003), which incorporate the widely used adaptation of snow making. As a result, Scott (2005) suggested that many studies likely overestimate the risk that climate change scenarios pose to ski area operators.

The focus of recent climate change and ski tourism research in North America has been on modeling potential decreases in ski season length, while considering the increasing snowmaking requirements necessary to compensate for the projected reductions in natural snow availability (see Scott et al. 2003, 2006, 2007, 2008, Dawson \& Scott 2007). When snowmaking was accounted for, Scott et al. $(2003,2006,2007)$ found that the vulnerability of ski areas in the Canadian provinces of Ontario and Quebec was reduced substantially compared to that reported in earlier studies that did not include snowmaking (McBoyle \& Wall 1987, 1992, Lamothe \& Périard Consultants 1988).

A major limitation of the modeling based approach is an understanding of how changes in season length and snowmaking requirements will affect skier demand patterns as well as operating costs and profitability of ski areas. This knowledge gap is partially related to the proprietary nature of information from ski area businesses. It is generally hypothesized that ski area expenditures will rise due to increased snowmaking requirements, which will in turn augment labour and energy/fuel expenditures as well as water requirements. Increases in operating costs will be greater for ski areas located at lower elevations where more snowmaking will be required in comparison to ski areas located at cooler, higher altitudes (Dawson \& Scott 2007).

These research limitations can be overcome by using a climate change analogue approach to assess the potential impacts on supply- and demand-side indicators that are available from the ski industry. As Scott (2005) noted, the analogue approach has been under-utilized in climate change and tourism studies although it has the potential to offer new insights into future impacts and effectiveness of adaptations. For example, Scott (2005) found that the decline in skier demand in a 2050s analogue winter in Eastern North America is only 10 to $15 \%$, which is far less than survey studies of hypothetical behaviour change have projected (e.g. König 1998, Behringer et al. 2000). The analogue approach is a useful method for identifying the possible future impacts of global climate change, as they assess impacts during real events and include adaptation strategies and business decisions made during an anomalous 'short term' event, which may become the norm in the future. A key advantage of the climate change analogue approach is that it captures the full range of supply- and demand-side adaptations by ski operators, marketers and skiers.

Similar to modeling approaches, a limitation of an analogue methodology is the inability to predict future influencing conditions, including technological advances (advanced snowmaking), changing behavioural responses (substitution behaviour), changing demographics and increasing price of energy for transportation and ski area operations. In addition, analogues are only available for short to medium term time frames, since few analogue situations have occurred that are representative of longrange modeled climate futures under high greenhouse gas (GHG) emission scenarios (e.g. 2070-2099 A1fi from IPCC 2001).

The use of analogues in the climate change and tourism literature has thus far been extremely limited (see Giles and Perry 1998, Scott 2005). As mentioned, Scott (2005) examined skier demand compared with skier responses in eastern Canada and the USA during anomalously warm seasons. More generally, Giles \& Perry (1998) found that the dry and warm UK summer of 1995 resulted in decreased outbound tourism compared to average climatic years.

The analogue approach requires that data on impact indicators be available for both climate change analogue periods and climatically normal periods (baselines). The National Ski Areas Association (NSAA) has conducted an annual review of the state of the ski industry in the USA since 1973 through a detailed survey of its membership (NSAA 2009). The data submitted by individual ski operators is aggregated to produce regional results (i.e. for the Northeast, Southeast, Midwest, Rocky Mountains and Pacific West) in order to protect the proprietary nature of sensitive business information. This regional ski industry data was utilized in the present analogue study. Although NSAA data is available for all 5 ski regions in the USA, to explore the value of the analogue approach, the present study focused only on the Northeast region, where previous modeling studies revealed notable vulnerabilities.

The USA Northeast ski region (Fig. 1), which includes the states of Connecticut, Maine, Massachusetts, New Hampshire, New York, Rhode Island and Vermont, consists of 103 ski areas ranging from $137 \mathrm{~m}$ above sea level (m asl) to 1353 m asl (GoSki 2008, USGS 2008). Although mountains in this region represent some of the highest ski area elevation in eastern North America, many ski resorts in the area have base levels lower than $450 \mathrm{~m}$ asl. These lower resorts are expected to be particularly vulnerable under warming trends because of a reduced season length and the aforementioned increase in costs due to increased snowmaking (Scott et al. 2008). 


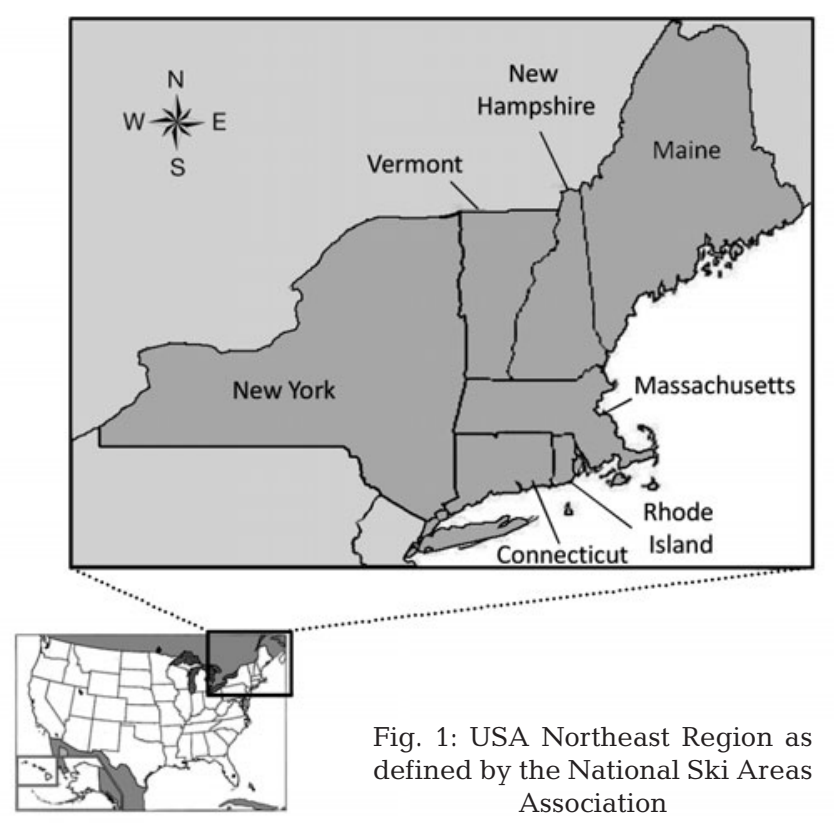

Skiing in the USA Northeast is not only culturally important, it is also economically significant. Participation in snow-based activities in the region is estimated to contribute US\$ 4.6 billion to the USA Northeast economy annually (Southwick Associates 2006). Individuals ski an average of 10 times per season in the USA Northeast, which is the highest participation rate in the country (NSGA 2005). Of all ski regions in the USA, the Northeast consistently records the second highest total visitation rate (average $\sim 13.5$ million skiers), second only to the Rocky Mountain region (average 19 million) (NSAA 2001, 2004, 2005)

\section{METHODS}

In the present study, a climate change analogue approach is used to examine how a wide range of ski area performance indicators were affected by anomalously warm winters in the USA Northeast region. Although an analogue assessment of individual ski areas would be a fruitful exercise, the present study examines climate change impacts at a regional scale because individual ski area information is not available due to the proprietary nature of specific business information. Two types of regionally aggregated annual NSAA reports, the Kottke End of Season Survey and the Economic Analysis of USA Ski Areas, are publicly available (NSAA 2009) and provide operational performance information on USA Northeast ski areas for the past 2 decades. Performance indicators were compared between climatically normal (average for the 1961-1990 period) versus anomalously warm winters to determine the impact of warmer temperatures, which are considered analogues for normal winter conditions under future climate change scenarios.

Historic temperature and precipitation data for the USA Northeast was derived from the National Oceanic Atmospheric Association, National Climate Data Center (NOAA 2008). Temperature data were primarily used to choose the analogue seasons, but precipitation was also considered. In 2001-2002, the USA Northeast region experienced a record warm winter season $\left(+4.4^{\circ} \mathrm{C}\right.$ above $1961-1990$ average) that is representative of projected future average winter temperatures under a high GHG emission scenario (ccsmA1B) for the 2040-2069 time period (for detailed regional climate change projections see Hayhoe et al. 2008, Frumhoff et al. 2008, and Pacific Climate Impacts Consortium 2008). Future winter precipitation for the USA Northeast is projected to increase by $30 \%$ under a high GHG scenario (A1fi) by the end of the century (Hayhoe et al. 2008). During the 2001-2002 season, precipitation decreased $20 \%$ below the 1961-1990 average. Because of this, the impacts experienced during this analogue season do not exactly portend those of climate change scenarios and, in the present study, may overestimate the impacts for ski areas at higher elevations. For example, it is important to consider both the benefits and drawbacks of increased precipitation under warmer temperature regimes for ski areas in this region. Increased precipitation could still fall as snow at higher elevations under mid-century scenarios but may fall as rain at lower elevations, which could exacerbate the impacts at lower-lying ski areas.

A ski area may rebound financially after experiencing one poor snow season amongst a series of average or above average seasons. However, it is much more difficult to financially recover after experiencing 2 or 3 poor seasons consecutively (Scott \& McBoyle 2007). To account for this, a second analogue period (the 1998-1999 ski season) was chosen, as it represents the last of 3 consecutively warm winters (1996-1999) that are representative of a mid-range GHG scenario (ccsmB1) for winter conditions during the 2040-2069 time period $\left(+2.7^{\circ} \mathrm{C}\right.$ above the $1961-1990$ average $)$. During the 1998-1999 season, precipitation was $7.5 \%$ above the 1961-1990 average. Precipitation projections for the 2040-2069 time period under a mid-range GHG scenario (B1) is $+20 \%$; therefore, the mid-range emissions analogue in the present study provides a reasonable proxy for both future temperature and precipitation.

The climatic analogue seasons (2001-2002 and 1998-1999) chosen for the present study are representative of some of the most marginal natural snow seasons experienced within the USA Northeast over the past 112 yr. The 2001-2002 climatic analogue is representative of the warmest winter season on record 
(NOAA 2008) and the 1998-1999 season represents the highest average winter temperature ever recorded for the third of 3 consecutive above average seasons.

It can be inferred that anomalies that occurred in ski resort operations during the analogue seasons may in turn become normal operating conditions in the 20402069 time period if temperatures rise in the region as projected under some climate change scenarios. Regional ski area information, including ski season length, snowmaking requirements, visitation and operating profits from the analogue years are compared with ski area information from the 2000-2001 and 2004-2005 seasons, which are representative of climatically average conditions for the region, compared to the 1961-1990 baseline period.

The climatic average (2000-2001 and 2004-2005) seasons used in the present study were chosen from winter climate data from the past 12 yr that best represent the 1961-1990 climatic average (temperature and precipitation) for winter seasons (December to February) (NOAA 2008). These seasons represent the second and third best representations of an average season in the region for the past $112 \mathrm{yr}$. The absolute best climatologically average year actually occurred in 1987, prior to the large-scale regional expansion of snowmaking, which was not complete until the mid to late 1990s. Because snowmaking is an integral part of ski area operations today, the climatically normal year 1987 was not used in the present study as it was not directly comparable to current standard operating conditions in the study area. Furthermore, other major factors influencing ski business were different $20 \mathrm{yr}$ ago (e.g. ski participation rates, interest rates, travel costs, ski business models). Since the mid-1990s, ski area business models have stayed reasonably consistent (i.e. heavy real estate development, diversified revenue sources, establishment of conglomerates), therefore allowing for a more reliable comparison between marginal and average ski area performance during this timeframe. Normal baseline years were selected as close to the analogue years as possible in order to minimize the influence of other major factors that affect the ski industry over time frames of 1 to 5 yr (e.g. general economic conditions, fuel prices, new competitors, growth-recession, interest rates). By carefully selecting baseline years for comparison, the influence of climate variability is isolated as much as possible. However, the extent to which other major business factors were controlled for by using this method remains uncertain.

In the present study, ski area performance indicators for the 2001-2002 (high GHG) and 1998-1999 (midrange GHG) analogue years were compared with indicators for the climatically normal (compared to the 19611990 average) years of 2000-2001 and 2004-2005. Ski area size, measured by capacity (vertical transport feet per hour [vtf h $\mathrm{h}^{-1}$ ], see NSAA 2008), was also analyzed. Finally, the impacts revealed for the climate change analogue years (1998-1999 representative of a mid-range GHG scenario and 2001-2002 representative of a high GHG scenario) were compared with previously modeled season length data for the 2040-2069 time period in the USA Northeast region (modeled data found in Dawson \& Scott 2007 and Scott et al. 2008).

\section{RESULTS}

This section compares the physical indicators (snowfall, season length, and snowmaking requirements), demand indicators (skier visitation) and economic indicators (operational profit) between the analogue years and climatically normal years.

\subsection{Physical indicators}

Four physical indicators were examined, including natural snowfall in inches (as reported by ski areas, not climate stations), snowmaking hours, percentage of energy utilized for snowmaking and ski season length. During the climatically normal years of 2000-2001 and 2004-2005, the average snowfall reported by ski areas in the USA Northeast region was $447 \mathrm{~cm}$. During the analogue seasons of 1998-1999 (consecutive season mid-range analogue) and 2001-2002 (single season high GHG analogue), only 274 and $272 \mathrm{~cm}$ of natural snow fell, respectively, leaving ski areas with almost $40 \%$ less natural snow than during climatically average seasons.

Less natural snowfall during the analogue years forced ski areas to rely more heavily on snowmaking to make up for poor snow coverage, particularly early in the season. Snowmaking hours increased by 75.8 and $11.4 \%$ in the 1998-1999 and 2001-2002 analogue seasons, respectively, in comparison to the climatically average years. The significant increase in snowmaking hours during the 1998-1999 three-season analogue in comparison to the 2001-2002 single-season analogue is likely due to a combination of factors. In the 19981999 season, precipitation and percentage of precipitation falling as snow were well below average in the months of November and December. Snowfall was below average during the 2001-2002 season, but not as severely below average as during the 1998-1999 season. Due to low early season snowfall in 1998-1999, ski area operators likely increased snowmaking hours during this very important part of the ski season to ensure there was a sufficient base to open and also to avoid any unwanted closures during the economically important Christmas/New Year holiday period. Addi- 
tionally, during the month of December of the 20012002 season, the average temperature for the region was only $29.3^{\circ} \mathrm{F}\left(-1.5^{\circ} \mathrm{C}\right)$, meaning that there were relatively few periods with extended temperatures of at least $23^{\circ} \mathrm{F}\left(-5^{\circ} \mathrm{C}\right)$ or cooler, which is required for efficient snowmaking (see Scott et al. 2003). With a high probability of losing machine-made snow to warm daytime temperatures and liquid precipitation events, many ski areas would not even attempt to make snow at lower elevations, thereby reducing snowmaking hours. Finally, the increased snowmaking hours influenced the amount of energy utilized for the purpose of creating snow by $37 \%$ (1998-1999) and 31\% (20012002) in comparison to average ski seasons. The fact that snowmaking hours increased so dramatically during the 1998-1999 season in comparison to both the average season and the single-season analogue while the percent energy utilized for snowmaking did not increase proportionally also suggests that snowmaking capacity or snowmaking efficiency may have increased between 1998 and 2002.

The limited natural snow cover and increased snowmaking that occurred during the 1998-1999 and 2001-2002 ski seasons also had an effect on average ski season length. Season lengths were $3.4 \%$ (1998-1999) and 10.9\% (2001-2002) shorter than during average seasons, totaling an average season reduction of almost 2 wk for the high GHG analogue (Table 1).

When examining the differential vulnerability of ski areas, season length was found to be positively correlated with size of resort. The smaller resorts consistently experienced the greatest loss in season length during both analogue years followed by medium, large and then extra large ski areas (Table 2).

\subsection{Demand indicators}

Marginal snow conditions and shorter seasons have an impact on ski area visitation. During the 2000-2001 and 2004-2005 average ski seasons, USA Northeast ski areas drew more than 13.5 million skier visits. Visitation during the climate change analogue seasons of 1998-1999 and 2001-2002 drew 10.8 and $11.6 \%$ fewer visits, respectively (Table 3).

\subsection{Economic indicators}

The combination of increased snowmaking costs, decreased season lengths and lower visitation rates inevitably increases operational costs for energy/fuel, labour and machine maintenance, and reduces revenues from lift passes as well as other related spending (i.e. ski rentals, lessons, food and beverages, and accommodation). Examination of economic data for the USA Northeast region shows that operating profit as a percent of gross fixed assets (gfa) (i.e. excluding depreciation and/or amortization) show almost no change for the 1998-1999 climatically marginal season (mid-range GHG analogue), but a very significant decrease during the 2001-2002 climatically mar-

Table 1. Effect of climate change on ski resorts. Normal conditions are mean of the years 2000-2001 and 2004-2005; conditions in 1998-1999 correspond to the mid-range scenario (ccsmB1) and in 2001-2002 to the high emissions scenario (ccsmA1B) for 2040-2069. (\% change from normal is given in parentheses)

\begin{tabular}{|lcccc|}
\hline & Normal & \multicolumn{2}{c|}{$\begin{array}{c}\text { Climate change analogue } \\
1998-1999\end{array}$} & $\begin{array}{c}\text { 2001-2002 } \\
\text { (high emissions) }\end{array}$ \\
& & & (mid-range) & \\
\hline Natural snowfall (cm) & & 447 & $274(-38.6)$ & $272(-39.2)$ \\
Snowmaking & Time (h) & 930 & $1635(+75.8)$ & $1036(+11.4)$ \\
& Energy (\%) & 40 & $54(+36.7)$ & $52(+31.4)$ \\
Season length (d) & & 132.5 & $128(-3.4)$ & $118(-10.9)$ \\
& & & & \\
\hline
\end{tabular}

Table 2. Length of season at ski resorts of different size in normal and climate change analogue years. (\% change from normal is given in parentheses). Resort capacity is in vertical feet per hour (see NSAA 2007). See Table 1 for definition of climate change scenarios

\begin{tabular}{|lcccc|}
\hline & \multirow{2}{*}{$\begin{array}{c}\text { Capacity } \\
\left(10^{3} \mathrm{vtf} \mathrm{h}^{-1}\right)\end{array}$} & Normal & $\begin{array}{c}\text { Season length }(\mathrm{d}) \\
\text { Climate change analogue } \\
\text { 1998-1999 }\end{array}$ & $\begin{array}{c}\text { 2001-2002 } \\
\text { (mid-range) }\end{array}$ \\
\cline { 3 - 5 } & & & $99(-9.2)$ & $87(-20.2)$ \\
Small & $0-2999$ & 109 & $125(-5.3)$ & $119(-9.9)$ \\
Medium & $3000-5999$ & 132 & $135(-2.9)$ & $133(-4.3)$ \\
Large & $6000-11999$ & 139 & $173(+8.3)$ & $153(-3.8)$ \\
Extra large & $>12000$ & 160 & & \\
\hline
\end{tabular}

Table 3. Demand $\left(\times 10^{6}\right.$ skier visits) and operating profit ( $\%$ of gross fixed assets) in normal and climate change analogue years. (\% change from normal is given in parentheses). See Table 1 for definition of climate change scenarios. Resort size defined in Table 2

\begin{tabular}{|lcccc|}
\hline & Resort size & Normal & \multicolumn{2}{c|}{$\begin{array}{c}\text { Climate change analogue } \\
1998-1999\end{array}$} \\
& & 2001-2002 \\
& & & $12.3(-10.8)$ & $12.2(-11.6)$ \\
(mid-range) & high emissions) \\
\hline Visits $\left(\times 10^{6}\right)$ & & 13.8 & $13.1(+2.4)$ & $8.6(-32.6)$ \\
Profit $(\%)$ & & 13 & $10.5(-27.7)$ & $8.7(-40.4)$ \\
& Small & 14.5 & $11.6(+3.5)$ & $11.7(+4.6)$ \\
& Medium & 11.2 & $10.0(+2.5)$ & $8.0(-17.4)$ \\
& Large & 9.7 & $14.4(-12.4)$ & $7.9(-51.5)$ \\
& Extra large & 16.4 & & \\
\hline
\end{tabular}


ginal season (high GHG analogue). The 2001-2002 season experienced average winter temperatures $+4.4^{\circ} \mathrm{C}$ higher than the climatically normal temperatures for the 1961-1990 baseline period, greatly increasing the necessity for snowmaking and the concomitant cost of snowmaking during this anomalously warm season. Operating profits for the 2001-2002 season were $33 \%$ lower than during a climatically average season (Table 3). Importantly, while these represent substantial reductions, the ski industry as a whole still operated in a profitable position in the region.

Declines or increases in specific revenue sources during the analogue years were also examined. During the mid-range GHG analogue, lift ticket sales decreased by $9 \%$, food and beverage sales decreased by just over $5 \%$, equipment rentals decreased by $20 \%$ and all other sales increased by $3.5 \%$. During the high GHG analogue, lift ticket sales remained very close to average $(+2 \%)$, suggesting that skiers adapted to poor early season conditions and visited more frequently in mid to late season. Other revenue areas were affected differently, with food and beverage sales decreasing by almost $8 \%$, equipment rentals decreasing by $1 \%$ and retail increasing by almost $8 \%$. It is difficult to conclusively say why these revenue sub-sectors were affected differently. However, it is possible that skiers who normally ski full days instead skied for half days during the marginal conditions, therefore decreasing food and beverage profits. Marginal conditions may have also enticed skiers to participate more in shopping activities instead of skiing.

When examining the differential vulnerability of ski areas, the correlation between climatic conditions and operating profits was less clear than observed for season length. This data suggests that medium and large ski areas generally fare better economically during climatically marginal winter seasons than small or extra large ski areas (Table 3).

\section{DISCUSSION}

In the present study, an analogue approach was used to examine a variety of physical, demand and economic impacts experienced by ski areas in the USA Northeast region during unusually warm winters that are anticipated to be representative of average climatic conditions in the future. The discussion focuses on 3 key findings: differences between the effects of a single warm season compared to consecutive warm seasons, differences between climate change analogue and modeled season length data, and differential impacts among the size of ski areas.

\subsection{High GHG single season versus mid-range GHG consecutive season analogues}

The 1998-1999 season was chosen to represent a mid-range GHG analogue for the period 2040-2069 and is the third of 3 consecutive marginal ski seasons. The 3 seasons occurring between 1996-1997 and 1998-1999 all experienced average temperatures of at least $+2.5^{\circ} \mathrm{C}$ above the $1960-1991$ climatic average. Results indicate that, during the third warm season (1998-1999), ski areas experienced significant increases in snowmaking hours $(+75 \%)$ and costs $(+37 \%$ energy required), a shortened ski season ( $-5 \mathrm{~d})$, and an $11 \%$ loss in visitation, but still managed to produce a profit at the regional level. In this example of consecutively marginal seasons, ski area operators appear to have adapted well to warmer conditions, likely having learned from experience in the 2 previous warm winters. Revenues per skier visit during the 1998-1999 season were almost US\$ 5 higher per person than in average years (in part due to increased shopping activities), which partially explains the slight increase in operating profit despite decreased ticket sales and visitation combined with increased snowmaking costs. Revenue generated from rental equipment was significantly reduced during this season $(-20 \%)$, suggesting that fewer new/beginner skiers participate in skiing during years with marginal snow conditions.

Ski area operators do not appear to have adapted as well to marginal conditions during the 2001-2002 record warm season. Snowmaking requirements increased by $12 \%$ (h operated), causing a $31 \%$ increase in energy utilized for snowmaking. Season length decreased by $15 \mathrm{~d}$, visitation was down by almost $12 \%$ and operating profits declined by as much as $32 \%$. The stronger effects can be attributed both to worse climatic conditions (high GHG analogue for the 20402069 time period) and the possibility that ski areas were less prepared than in the 1998-1999 season, which was the third consecutive poor season.

\subsection{Modeled season length versus analogue results}

Scott et al. (2008) modeled ski season lengths in the USA Northeast region for the 2040-2069 time periods using 6 climate change scenarios composed of 3 Global Climate Models, each run under 2 IPCC-SRES emission scenarios, representing a high GHG future (A1Fi with an atmospheric $\mathrm{CO}_{2}$ concentration of $970 \mathrm{ppm}$ ) and a low GHG future (B1 $-550 \mathrm{ppm}$ ). The regionally averaged 1961-1990 baseline ski season was modeled to be $132 \mathrm{~d}$, which compares well to the $133 \mathrm{~d}$ reported for the 2 climatically average years in the present study (see Table 1). Ski seasons were projected by Scott et al. 
(2008) to decline to $116 \mathrm{~d}$ in the mid-range GHG scenario for the 2040-2069 time period, which is a greater reduction than observed in the mid-range GHG analogue (1998-1999) of $128 \mathrm{~d}$. For the high GHG scenario in the 2040-2069 time period, ski season length was projected to decline to $108 \mathrm{~d}$ under a high GHG scenario (A1fi), which again is less than observed in the high GHG analogue (2001-2002) in the present study (118 d).

The differences between modeled season length data and analogue data can be explained by the inability of physically-based snow modeling techniques to account for business management adaptations (i.e. opening under even very marginal conditions because of staffing inflexibility and to provide some level of skiing, perhaps only 1 or 2 runs, to guests staying in resort accommodations), which can lead to the overestimation of impacts.

\subsection{Differential vulnerability among ski areas}

In their analysis of the climate change vulnerabilty of the USA Northeast winter recreation tourism sector, Scott et al. (2008) concluded that it is not the entire ski industry in the region that is at risk to climate change, but rather individual ski businesses and communities that rely on ski tourism. This is because individual ski areas have a range of technical snowmaking capabilities, are situated at varying elevations and have different business models (i.e. are of different sizes, provide winter vs. four-season activities, have different ownership structures and access to capital). The majority of ski areas in the Northeast have substantial snowmaking capabilities, meaning that the few that do not make snow are significantly disadvantaged and will require substantial investment in order to survive under projected warmer climatic conditions in the future. Ski areas located at higher elevations in the USA Northeast are inherently at an advantage, due to lower mean temperatures and a greater proportion of winter precipitation falling as snow. Ski areas situated at higher elevations experience fewer marginal natural snow conditions and are able to produce machine-made snow more often and at lower costs than lower-lying ski areas (i.e. machine-made snow typically requires temperatures of $23^{\circ} \mathrm{F}$ [ $-5^{\circ} \mathrm{C}$ ] or colder to be produced efficiently; Scott et al. 2003). Finally, medium to large ski areas can be at an advantage, as they can usually support a larger client base on any operating day, therefore generating higher revenues. They also typically have multiple activities, including indoor activities that do not rely on snow and that visitors can engage in when snow conditions are poor. Furthermore, larger ski areas in the USA Northeast are gener- ally situated at higher elevations than smaller ski areas.

In the present study, key indicators (season length and operating profit) were analyzed by resort size. Season length was influenced by the size of a ski area. For example, the smaller the ski area, the more significant the loss in season length that can be expected during future warming regimes. A size-based correlation for economic indicators was less clear; this was likely a result of the different acumen and decisions made by different ski area operators. Medium and large ski areas generally fare better during climatically marginal winter seasons than small or extra large ski areas. This may be due to some lower-lying small resorts not having sufficient snowmaking capabilities, which makes it difficult for them to stay operational for the duration of a marginal season. Extra large ski areas may struggle to keep a larger area operational and may, in doing so, require significant expenditure because of increased snowmaking in comparison to medium or even large ski areas. In addition, extra large ski areas may have less flexibility with personnel and may be unable to temporarily lay people off. The differential vulnerability among ski areas observed in the present study suggests that small ski areas located at low elevations are most likely to experience the greatest impact from future climate change.

\section{CONCLUSIONS}

The objective of the present study was to examine climate change vulnerability of the USA Northeast ski tourism industry using a historic analogue approach. Using mid-range and high GHG analogues for the 2040-2069 time period, it was revealed that, under anticipated climate change conditions, ski areas will experience substantial impacts, including increased snowmaking requirements and operational costs along with decreased visitation and operating profits. However, adaptation measures look promising for the ski tourism industry, not only because they have access to technologies that will aid in operation (i.e. snowmaking), but also because the third-consecutive season analogue suggests that business decisions and adaptation measures implemented early are successful in reducing consecutive season impacts during marginal conditions similar to those expected in future decades.

Analogue data suggest that the lowest, smallest and very large resorts are more vulnerable than medium and large resorts and, as a result, may incur higher adaptation costs than the latter. In the future, ski areas that are able to afford the cost of adapting to climatic changes expected over the next 3 to 5 decades are most likely to survive. The analogue data suggest that even higher adap- 
tation costs should be expected by all ski area operators in the region under the high GHG scenario. This is generally consistent with modeling-based studies in the region. Importantly, adaptations by ski businesses appear to have reduced the impacts of warm winters, as reductions in season length in the climate change analogue years were consistently lower than those projected in modeling-based studies.

An analogue for the 2070-2099 time period was not available for the USA Northeast region; therefore, the analysis of impacts expected to occur during this future timeframe was not possible. Because the industry has not yet experienced temperatures similar to those projected for 60 to $90 \mathrm{yr}$ from now, modeling remains an important method for examining long-term impacts. Combining information from an analogue assessment with modeled data is likely to be the most useful approach in understanding the net climate change vulnerability of the ski tourism industry.

Future analogue-based research within the ski tourism sector will provide a clearer picture of the effectiveness of adaptation in different parts of the USA and elsewhere. Specifically, future research might include the calibration of demand and profit indicators to season length, in order to provide greater understanding of the implications of season length projected in modelbased studies. A more detailed analysis of indicators based on the size of ski resorts at an individual ski business scale would be fruitful in determining the relative vulnerability of ski areas to climate change, and would allow for a more specific determination of how the regional ski market may evolve over time. Determining where the ski industry might contract and which communities may need to prepare to adapt to the related economic loss, as well as which communities may need to prepare for development pressures (e.g. water use for snowmaking, real estate development, slope expansion, congestion) associated with the concentration of ski tourism in fewer areas, should also be a priority for future research.

Acknowledgements. We acknowledge the NSAA for providing the reports required for the present study.

\section{LITERATURE CITED}

Abegg B, Agrawala S, Crick F, De Montfalcon A (2007) Climate change impacts and adaptation in winter tourism. In: Agrawala S (ed.) Climate change in the European Alps: adapting winter tourism and natural hazards management. Organization for Economic Cooperation and Development, Paris, p 25-58

Behringer J, Buerki R, Fuhrer J (2000) Participatory integrated assessment of adaptation to climate change in alpine tourism and mountain agriculture. Integrated Assess 1: $331-338$
Bicknell S, McManus P (2006) The canary in the coalmine: Australian ski resorts and their response to climate change. Geogr Res 44:386-400

Breiling M, Charamaza P (1999) The impact of global warming on winter tourism and skiing: a regionalized model of Austrian snow conditions. Reg Environ Change 1:4-14

Casola J, Kay J, Snover A, Norheim R, Binder L (2005) Climate impacts on Washington's hydropower, water supply, forests, fish and agriculture, Centre for Science and the Earth System, University of Washington, Seattle, WA

Dawson J, Scott D (2007) Climate change vulnerability of the Vermont ski tourism industry (USA). Annal Leisure Res 10:550-572

> Elsasser H, Bürki R (2002) Climate change as a threat to tourism in the Alps. Clim Res 20:253-257

> Elsasser H, Messerli P (2001) The vulnerability of the snow industry in the Swiss Alps. Mt Res Dev 21:335-339

> Frumhoff PC, McCarthey JJ, Melilo JM, Moser SC, Wuebbles DJ, Wake C, Spanger-Siegfried E (2008) An integrated climate change assessment for the Northeast USA. Mitig Adapt Strategies Glob Change 13:419-423

- Fukushima T, Kureha M, Ozaki M, Fujimori Y, Harasawa H (2002) Influences of air temperature change on leisure industries: case study of ski activities. Mitig Adapt Strategies Glob Change 7:173-189

Galloway RW (1988) The potential impact of climate changes on Australian ski fields. In: Pearmann GI (ed) Greenhouse: planning for climate change. CSIRO, Melbourne, p 428-437

Giles AR, Perry AH (1998) The use of a temporal analogue to investigate the possible impact of projected global warming on the UK tourist industry. Tourism Manage 19:75-80

Hayhoe K, Cayan D, Field C, Frumhoff P and others (2004) Emissions pathways, climate change and impacts on California. Proc Natl Acad Sci USA 101:12422-12427

Hayhoe K, Wake C, Anderson B, Liang XZ and others (2008) Regional climate change projections for the Northeast USA. Mitig Adapt Strategies Glob Change 13:425-436

Hennessy K, Whetton P, Smith I, Bathols J, Hutchinson M, Sharples J (2003) The impact of climate change on snow conditions in mainland Australia. CSIRO Atmospheric Research, Victoria, Australia

IPCC (Intergovernmental Panel on Climate Change) (2001) Special report on emissions scenarios. IPCC, Geneva

König U (1998) Tourism in a warmer world: implications of climate change due to enhanced greenhouse effect for the ski industry in the Australian Alps. University of Zurich, Zurich

Koenig U, Abegg B (1997) Impacts of climate change on tourism in the Swiss Alps. J Sustainable Tourism 5:46-58

Lamothe \& Périard Consultants (1988) Implications of climate change for downhill skiing in Quebec. Climate Change Digest 88-03, Environment Canada, Ottawa

Lipski S, McBoyle G (1991) The impact of global warming on downhill skiing in Michigan. East Lakes Geographer 26: 37-51

McBoyle G, Wall G (1987) The impact of $\mathrm{CO}_{2}$ induced warming on downhill skiing in the Laurentians. Cah Geogr Que 31:39-50

McBoyle G, Wall G (1992) Great Lakes skiing and climate change. In: Gill A, Hartman R (ed) Mountain resort development. Simon Fraser University, Centre for Tourism Policy and Research, Burnaby, BC, p 71-81)

> Moen J, Fredman P (2007) Effects of climate change on alpine skiing in Sweden. J Sustainable Tourism 15:418-437

NSGA (National Sporting Goods Association) (2005) Sports participation study, 2005 calendar year. NSGA, Illinois 
NOAA (National Oceanic and Atmospheric Assocation) (2008) Climate. Accessed 19 March 2007, www.noaa.gov/ climate.html

NSAA (National Ski Areas Association) (2001) Kottke national end of season survey 2000/01 (22nd). NSAA, Lakewood, CO

NSAA (2004) Kottke national end of season survey 2003/04 (25th edn.). NSAA, Lakewood, CO

NSAA (2005) Kottke national end of season survey 2004/05 (26th edn.). NSAA, Lakewood, Colorado

NSAA (2007) Kottke national end of season survey 2006/07 (28th edn.). NSAA, Lakewood, CO

NSAA (2008) 2007/08 Economic analysis of United States ski areas. NSAA, Lakewood, CO

NSAA (2009). Available Research. Accessed 30 March 2008, www.nsaa.org/nsaa/marketing/availableResearch.asp

Pacific Climate Impacts Consortium (2008). Resources/Climate Impacts. Accessed 12 July 2008, http://pacificclimate.org/ resources/climateimpacts/

Perry AH (1997) Recreation and tourism. In: Thompson RD, Perry AH (ed) Applied climatology. Routledge, London, p 240-248

Scott D (2005) Global environmental change and mountain tourism. In: Gössling S, Hall CM (ed) Tourism and global environmental change: ecological, social, economic and political interrelationships. Routledge, London, p 54-75

Editorial responsibility: Helmut Mayer, Freiburg, Germany
Scott D, McBoyle G (2007) Climate change adaptation in the ski industry. Mitig Adapt Strategies Glob Change 12: 1411-1431

Scott D, McBoyle G, Mills B (2003) Climate change and the skiing industry in southern Ontario (Canada): exploring the importance of snowmaking as a technical adaptation. Clim Res 23:171-181

Scott D, McBoyle G, Mills B, Minogue A (2006) Climate change and sustainability of ski-based tourism in eastern North America: a reassessment. J Sustainable Tourism 14: 376-398

Scott D, McBoyle G, Minogue A (2007) The implications of climate change for the Québec ski industry. Glob Environ Change 17:181-190

Scott D, Dawson J, Jones B (2008) Climate change vulnerability of the USA Northeast winter recreation-tourism sector. Mitig Adapt Strategies Glob Change 13:577-596

Southwick Associates (2006) The economic contribution of active outdoor recreation. Outdoor Industry Foundation, Boulder, $\mathrm{CO}$

USGS (US Geological Survey) (2008) National elevation dataset. Accessed 12 July, 2008; http://ned.usgs.gov/

Wolfsegger C, Gössling S, Scott D (2008) Climate change risk appraisal in the Austrian ski industry. Tourism Rev Int 12(1): $13-23$

Submitted: July 31, 2008; Accepted: February 5, 2009 Proofs received from author(s): April 4, 2009 